Published in Theory, Culture \& Society, 9/1 (1992): 229-252. And in: Mike Featherstone (ed.), Cultural Theory and Cultural Change, London, Sage 1992, pp. 229-352.

\title{
On Status Competition and Emotion Management The Study of Emotions as a New Field
}

\author{
Cas Wouters
}

During the Gulf War fighter pilots, interviewed for TV in their planes before taking off, admitted to being afraid. They did this in a matter of fact way. This would have been almost unthinkable in World War II, when such behaviour would have been equated almost automatically with being fear-ridden, a condition in which it was thought to be impossible to perform well. The dominant response at that time, in answer to the problem of how to prevent soldiers from giving in to fear may be summarized in a quotation from a 1943 manual for American officers: it is the soldier's 'desire to retain the good opinion of his friends and associates ... his pride smothers his fear' (Stearns and Haggerty 1991). Precisely the same pride kept soldiers from admitting they were afraid, especially before an operation. At the time of the Gulf War, all this had obviously changed. Today, admitting one is afraid no longer means that one has automatically to act upon the emotion. It has become quite common to admit feeling this or that, and yet to act differently. This is an example of a change in the codes of behaviour and emotion management in the direction of an 'emancipation of emotions'; an example of the long-term process of informalization, in which behavioural, emotional and moral codes have relaxed and differentiated (Wouters 1986, 1987, 1989). This same process may help to explain why the study of emotions has emerged and is expanding in all the disciplines of the social sciences, including history.

From the mid-1970s onwards, interest in this subject has found expression in rapidly increasing numbers of psychological, sociological and historical studies, and in the formation of study groups within official academic associations. In the 1980s, the American and the British Sociological Associations both established 'sociology of emotions' study groups. Theodore Kemper, editor of a reader in the sociology of emotions, refers to 1975 as the watershed year (Kemper 1990). In that year, Arlie Hochschild published an influential article on emotions, Thomas Scheff organized the first session on emotions at the American Sociological Association meetings, and Randall Collins theorized a central place for emotions in his book Conflict Sociology. At present, the study of emotions is booming. 
This paper seeks to explain the rise and the rising importance of the study of emotions from the perspective of figurational or process sociology. The search for an explanation mainly consists of an attempt at connecting this rise to the social process of intensified status competition within increasingly dense networks of interdependency. From this perspective, a first clue is to be found in the fact that focusing on emotions and emotion management seems to have spread predominantly in Western societies, where increasing numbers of people have experienced rising degrees of physical safety and material security, in the course of which the dangers of violence and poverty have become less topical. In these parts of the world, one's individual style of emotion management has gained importance in the struggle for status and power, as a criterion in the process of ranking, whereas in most countries of the Third World, status criteria like 'birth' and wealth - referring to groups and their proximity to the centres controlling the dangers of violence and poverty - strongly dominate over other criteria. In the West, these dangers have diminished as political, economic and cultural networks of interdependency expanded and became more dense. Correspondingly, the more traditional status criteria like 'birth' and wealth have lost some weight, without becoming unimportant, whereas ranking criteria like individual merit and achievement, lifestyle and style of emotion management have gained in importance. ${ }^{1}$ In the same broad process, a wide range of emancipation movements have been established and ideals of equality have spread. Succeeding waves of democratization and the redistribution of economic surpluses according to welfarestate principles have resulted in the depletion or disappearance of the groups at either end of the social ladder, with a sharp increase of the jostling and status struggle in the middle. As hierarchical differences between individuals and groups diminished and bonds of cooperation as well as competition between increasing numbers of people expanded and intensified, all have increasingly exerted pressure upon each other to take more of each other into account more often. In this way, the sensitivity for each other's emotional life has increased, allowing for a wider social acceptance of all kinds of emotions, with the exception of feelings of superiority and inferiority. These emotions had to be increasingly curbed, as these movements and ideals have limited power to express social distance and distinction.

At the beginning of this century, in a still strongly hierarchical society like Wilhelminian Germany, status differences and related feelings of superiority and inferiority were still expressed directly and plainly:

Anyone who displayed any weakness counted for a nullity. Here, people were fundamentally trained to strike hard whenever they knew they were confronted with a weaker person, to demonstrate immediately and unmistakably their own superiority and to 
rub in the other's inferiority. Not to do that was weakness, and weakness was something contemptible (Elias 1989: 144).

According to the dominant code of the more egalitarian and democratic societies of today, such a plain display of superiority is no longer bon ton. On the contrary, it would bring a loss of status and face. Gestures and feelings of superiority have become more repugnant and are more easily met with moral indignation. This represents an advance in the threshold of shame and repugnance or embarrassment in the make-up of Western people, the development of a particular kind of drives/control balance (Elias 1978 and 1982). ${ }^{2}$ Not only transgressions like outbursts of physical - and sexual - violence, but also other ways of inflicting humiliation have increasingly come to be seen as intolerable displays of arrogance or self-aggrandizement, especially if based on biologically or socially inherited possessions and positions. They meet with stronger individual and collective repugnance and moral indignation. As subordinate social groups were emancipated, references to 'better' and 'inferior' kinds of people, to hierarchical group differences, were increasingly tabooed. ${ }^{3}$ But exactly because displaying these feelings has become such a strong threat to one's status and self-esteem, the insight that feelings of superiority and inferiority are inherently provoked by any status competition is often lost covered by status fears. The same goes for the insight that part of any encounter or gathering is a 'trial of strength', a power and status competition.

One of the difficulties in realizing these insights stems from the fact that in the same process of social equalization and democratization, the wish to defy this pressure - that is, the wish and the ideal of being able to articulate and distinguish oneself as an authentic individual, not just a group specimen, has simultaneously been stimulated and strengthened. To distinguish oneself from others gives value and meaning to one's own life, although it can only be done if one at the same time avoids any trace of feelings of superiority and inferiority, of violence, aggrandizement or other forms of humiliation. Ideally, avoidance of these traits should come 'naturally' or as the product of 'second nature', which means that it is done either unconsciously and automatically, or secretly. The complexity of this ideal may explain why references to feelings of superiority and inferiority, to the 'secret' part of emotion management, are soon felt to discredit the credibility or authenticity of individuals - and therefore their status, and why 'exposures' offer a view into the cauldron of emotion management that is often experienced as 'treacherous'. As Tom Wolfe observed: 'We are in an age when people will sooner confess their sexual secrets - much sooner in many cases - than their status secrets, whether in the sense of longings and triumphs or humiliations and defeats' (Wolfe 1976: 189). In Western societies of our time, discussing the importance of status for someone's identity has indeed become 
increasingly embarrassing and difficult. However, no matter how people try to keep their status secrets, even to intimates, a trained ear detects expressions of inferiority and superiority every day, whether in guarded terms or

in indirect and seemingly colourless terms which lacked the emotional directness with which people of higher status in less democratic ages spoke of their own superior status, but which, nevertheless, was quite unambiguous... The [status] yardsticks are almost always implied as part of an axiomatic communal belief system and the ranking is usually expressed by means of simple value terms which have the character of communal code words, such as 'better' or 'not quite nice', 'all right' or 'okay'... No individual grows up without this anchorage of his personal identity in the identification with a group or groups even though it may remain tenuous and may be forgotten in later life, and without some knowledge of the terms of praise and abuse, of the praise gossip and blame gossip, of the group superiority and group inferiority which go with it (Elias and Scotson 1965: 29, 41, 105).

Thus, on the one hand, contrasts in emotion management have diminished in contexts where feelings and displays of superiority and inferiority, inherently provoked by any competition, have become tabooed, repressed and denied, while on the other hand varieties in ways of managing emotions have increased in contexts where creating a particular impression, 'styling' or 'image building' within these borderlines has gained importance - and it has gained considerable importance. Impression management (cf. Goffman 1959) ${ }^{4}$ has even become a specialty, the job of an increasing number of emotional labour specialists (cf. Hochschild 1983) working in advertising bureaux, departments of Public Relations and in an enormously expanding service industry. Particularly with regard to styles of emotion management, status competition has intensified. The rising importance of emotion management has in turn stimulated an awareness of this management as well as curiosity about what exactly is managed, how it is done, and why.

Thus, the development towards intensified status competition within increasingly dense interdependency networks has exerted seemingly opposing pressures, conceptualized by Norbert Elias as diminishing contrasts and increasing varieties in behaviour and emotion management (Elias 1982 II: 251-7; also Mennell 1985: 317-332). On the one hand, there is the pressure to repress feelings of superiority and inferiority, in which process they are often put behind some social and individual scene or 'cover'. This curbing of displays of superiority and inferiority represents a diminishing of contrasts in behaviour and emotion management. On the other hand, there is a pressure to 'discover', to gain greater awareness, and more curiosity. To experiment with new, and new combinations of, alternatives and lifestyles has become more important as one of the ways in which individuals are able to distinguish themselves from others - taste and style have gained importance as beacons. ${ }^{5}$ Attempts in this direction have created pressures towards an increase in socially accepted emotional and behavioural alternatives, towards 
informalization. This represents an increase in varieties in behaviour and emotion management.

In an attempt to show that the rising popularity of the study of emotions is part of this trend of diminishing contrasts and increasing varieties in behaviour and emotion management, I will first elaborate upon this trend by presenting some familiar examples from the history of violence and money, freedom and welfare.

\section{Changing Regimes of Power and Emotions: Violence and Money}

The main contrasts that have been diminishing are those in displays of superiority and inferiority as expressed in the use of physical and sexual violence. Expression of emotions and impulses that could possibly provoke the danger of outbursts of physical and sexual violence has been increasingly excluded from the spectrum of socially acceptable behaviour.

In the long period of peace and prosperity after the last World War, political emancipation and the presence of nuclear weapons have created a situation between states that has been summed up as Mutually Assured Destruction (MAD), in which states have exerted pressure on each other towards higher levels of Mutually Expected Self-Restraints (MES). Particularly within industrialized Western states the use of violence has become increasingly tabooed and constraints on violent impulses and emotions have expanded to all walks of life (cf. Stearns 1989). Even where until recently men as 'heads of the family' could let themselves go and behave in relatively passionate and unrestrained ways towards their 'own' wife and children, they have now come to be both morally and legally constrained to curb their violent and sexual impulses. The recent wave of collective moral indignation and embarrassment about sexual harrassment, rape in marriage, incest or other forms of lack of control in this context reinforces this constraint.

Also outside the family, on the streets, changes have taken place in the same direction. Street fighting, the most basic expression of ongoing struggles between families, neighbourhoods or classes, has become relatively rarer (Dunning et al. 1987). At present, the stage at which children and adults lose control, are overwhelmed by violent impulses and have to give in to them, has receded. In Western societies of the seventeenth and eighteenth century, the emphasis in anger control still rested on obedience, on social control rather than on individual control of emotions: 'This meant... that outside the hierarchical relations within which the control of obedience was meant to operate, there were no real standards for anger restraint... anger was not specifically reproved save when its expression contravened hierarchy' (Stearns and Stearns 1986: 23). 
In the course of centuries, these standards have developed. In this process, status anxiety - the fear of loss of face and status - particularly functioned as a motor toward repressing and denying the emotions that could lead to violence. Among growing parts of the population, people pressured each other to restrain themselves in more drastic and more automatic ways: Mutually Expected Self-Control of violent emotions and impulses increased. But, as fairly large groups remained poorly integrated into these nation-states, upper and middle class people for a long time continued to be afraid of this danger and to avoid as much as possible "contaminating contact with the spiritually inferior and the repugnant' (Van Zutphen van Dedem 1928: 162) - an example of status anxiety. Through emancipation movements the possibilities for this avoidance-behaviour decreased as social integration and equalization increased. ${ }^{6}$ Together with growing pressures toward closer and more alert observation of oneself and others, the fear for each other had to be brought under firmer control. Thus, a further rise in the level of mutually expected self-control came about, which, in turn, as a necessary condition, allowed for a less rigid social regulation and for a less rigid and more varied self-regulation, for informalization. In other words, this rising level of Mutually Expected Self-Restraints has allowed an 'emancipation of emotions' that destroyed the old conviction incorporated in the traditional mode of emotion management that being open to such emotions would almost irrevocably be followed by acting upon them. Violent impulses and emotions even came to be more and more recognized as regular and normal aspects of emotional life. They not only became accepted as conversation topics but more and more people also took the liberty to vent these feelings, accepting that they 'come up for air' every now and then. In this movement, cursing, calling each other all sorts of names, and making allusions to violence all seem to have spread (cf. Stearns and Stearns 1986: 229). In this way people provoke and test their own and each other's emotion management. This kind of behaviour signifies an experimenting with emotions and impulses that until recently were more rigidly denied and repressed. In this development, increasing numbers of people have become aware of emotions and temptations in circumstances where fears and dangers had been dominant before - the temptations of 'sex, drugs and rock and roll', of tax evasion, shoplifting, swearing, etc. This provocative and experimenting attitude can be understood as the direct counterpart of what has been called the 'equanimity of the welfare state' (Stolk and Wouters 1987). This equanimity refers to the decline in the fear of poverty resulting from the welfare state system. In the long period of peace and prosperity after World War II, physical safety and, through the spreading of wealth according to the principles of the welfare state, also material security have become much less problematic. A change in the structure of the state was mirrored 
in a change in the structure of fears and anxieties: 'social security' generated a greater personal security. ${ }^{7}$ This 'peace' in material respects functioned as a breeding ground in which much relational unrest took root: men found themselves in a sense competing with the state, as the welfare system weakened the traditional dependence of women on men. But this 'equanimity of the welfare state' was also soon accompanied by an increasingly intense competition in emotion management, as expressed in displays of confidence and in a 'quest for risks'.

At this point, Tom Wolfe's comparison of some changes in the 1960s and 1970s with those in the upper classes in London during the Regency period (roughly, 1800 to 1830), is illuminating. At that time, he writes,

Both young men and women of the upper classes were swept by nostalgie de la boue - a longing to recapture the raw and elemental vitality of the lower orders... The middle classes had so much new money they threw traditional social lines into great confusion in London... Wealth was no longer a buffer between the classes; but the old aristocratic manner of confidence was. The middle classes had money but lacked the confidence to be anything but ever more ornately respectable (Wolfe 1968b: 169). ${ }^{8}$

In recent decades wealth has spread almost explosively to many more classes than during the Regency Period, the importance of emotion management (of confidence) has increased, and the spectrum of socially accepted modes of expression has become much more colourful and varied.

Not only violent impulses, but also sexual impulses and emotions have been collectively brought under firmer individual control, and in this process the fear of sexual passions has diminished. How intense this anxiety has been may be inferred from the reactions of established groups in the 1920s, when the old tradition of chaperonage came to an end in the historical novelty of 'free' social intercourse between the sexes, particularly in dance halls and cinemas. The government of The Netherlands, for example, was worried enough to establish a government committee with the task of investigating the 'problem of dancing'. One of the recommendations in the committee's report (Rapport 1931) was a mandatory appointment of 'dancing masters' in charge of surveillance in dance halls. The emphasis in sexual control still rested on obedience, on social control rather than on individual control of emotions. The report displayed hardly any confidence in the 'self-surveillance' of both sexes and was written on the implicit assumption that both men and women would give in to their sexual desires if social control was lacking:

In the modern dances, the danger of sexual titillation has reached a degree that was absent before... And thus, every young girl that visits a public dancing hall runs the risk of being 'led' in a reprehensible way, unnoticed by the public, and against which she practically cannot defend herself. And than we still assume the favourable condition, that the will to defend herself is present. But how many... do not maintain the moral endurance, here required, and end up with the rendezvous (Rapport 1931: 31). 
The lack of any confidence in self-control is also clearly demonstrated in exclamations from that period such as 'if the bridle is removed, sexuality gallops' (Ritter 1933: 152). In contrast, the current collectively expected mode of emotion management implies that even when 'surveillance' (this social constraint) is absent, self-constraint will be strong enough to prevent sexual impulses from giving way to sexual violence. Stronger control over these impulses and emotions, along with the fear of losing this control and of losing face, function as a basic condition for enabling people to experiment with their impulses and emotions more frankly, provided this experimenting is done with mutual consent. This means that, by analogy with contests in which allusion is made to violence, in sexual encounters too, increasing numbers of people are sooner and more frequently able to provoke and challenge, while avoiding humiliation. To challenge, provoke, conquer fears and search for limits has become a popular kind of sport. This 'sport' is expressed not only in all sorts of social relationships, but also in ways of dressing: the warlike punk outfit and 'hot pants', for example, demonstrate provocative fantasies. And it is particularly prevalent in the realm of imagination and amusement: both sexual and violent emotions and impulses are more or less expressed in a wide variety of pornography - Tom Wolfe speaks of 'pornoviolence':

Violence is the simple, ultimate solution for problems of status competition, just as gambling is the simple, ultimate solution for economic competition. The old pornography was the fantasy of easy sexual delights in a world where sex was kept unavailable. The new pornography is the fantasy of easy triumph in a world where status competition has become so complicated and frustrating. (Wolfe 1976: 162)

The search for the limits of emotion management in mutual contests and provocations, and the pleasure of sniffing the dangers on the other side of the borderlines, may satisfy the yearning for risks and the quest for excitement in welfare-state societies (cf. Elias and Dunning 1986). This 'sniffing of dangers' can be taken quite literally sometimes, as is demonstrated by the words of a 23 year-old cocaine user: 'The first time you try some coke you're afraid because you don't know what it is. But you want to conquer that fear' (van Hunnik 1989: 505). This 'quest for risks and exitement' seems to have become just as typical in welfare-state societies as their equanimity.

In displays of confidence and in the 'quest for risks' too, people have pressured each other to greater awareness and knowledge of emotions and emotion management. This knowledge has created the feeling of a distance from these emotions themselves. This has intensified the quest for behaviour that is experienced as 'natural', 'relaxed', 'spontaneous', 'authentic' and 'informal,' and it has also created a nostalgic yearning for the experience of (non-violent) emotions of an intensity that completely takes up the self and consciousness. ${ }^{9}$ This 
may explain why the longing for gratifying emotional and sexual bonds seems to have grown stronger, and why losing oneself in making love and in orgasm, called the 'little death' for this reason (Bataille 1971), seems to have become more highly valued the more this form of status competition has intensified. It has become more strongly experienced as a road to uncomplicated and unreflected existence, the sublime romance of naturalness. The same goes for other arts and sports, and this may partly explain why in this century these activities have gained considerable mass following.

The now dominant mode of emotion management has apparently reached a strength and scope that enables people to admit violent and/or sexual emotions and impulses to themselves and each other, without provoking the fear of losing control and of having to give in to them. Only when the level of Mutually Expected Self-Restraints has risen to this level, do experiments in loosening restraints stand a chance of becoming successful. Otherwise, the 'decontrolling of emotional controls' is not sufficiently 'controlled' and is thus too risky. That is precisely the tenor of the story about a kindergarten where children were allowed to take their 'weaponry' along. The arms race and fights did not reach the saturation point that the parents had hoped and waited for. Paul Kapteyn concludes:

The increased tolerance and flexibility of adults towards the children's violence, this violation of a taboo, could only be understood and followed by the children when they had first become quite familiar with the taboo - when they had first learned what they later to some extent could unlearn (Kapteyn 1980: 179).

In this example, one may recognize a sequence that Piaget and Kohlberg incorporated in their models on intellectual and moral development, that is, the sequence in which children at first are pre-occupied with their own emotions and cling to the social routines of what they perceive as 'the done thing'. From the age of 11 or 12 onwards, role-taking and the balancing of their own feelings and the feelings of others become more generally possible. From then on, they may learn to individualize and improvise, that is, to choose their own strategy or procedure for this situation and in relation to that person. Thus, in this respect, in individual civilizing processes a similar structure can be discerned as in the civilizing processes of societies, in which the longterm process of informalization was preceded by a long-term process of formalization.

\section{Changing Regimes of Power and Emotions: Irritation and Nostalgia}

As rising numbers of people have been integrated into increasingly dense and democratized networks of interdependency, not only have demands on emotion management and awareness of it increased, but at the same time ambivalences and insecurities in emotion management and 
identity-formation have intensified. When more and more people were drawn into increasingly dense interdependency networks, people who earlier had avoided each other came at a later stage to have to (and also to wish to) relate to each other. In this process, the groups about which individuals had learned to say 'we' - we-groups - went through changes that forced them to adjust their we-identities and we-feelings. This kind of change, in many respects similar to the changes inherent to the process of growing up, affects different layers of personality and often creates an ambivalence, sometimes conceptualized as 'estrangement'. Entangled in these changes, many people have been drawn into a tug-of-war between old and new we-feelings. This pendulum sometimes swings heavily towards romanticizing old feelings and memories, even towards inventing them (cf. The Invention of Tradition, Hobsbawm and Ranger 1983). If this ambivalence finds expression in the romantic way, the changes in groups and in society at large are easily interpreted as predominantly oppressive, and irritation dominates. In these cases, the changes seem to have robbed individuals of their we-feelings or identification with some cohesive we-group. In their nostalgia, that 'melancholy yearning for a sense of belonging which is often seen as being in the past' (Bailey 1988: 31), the emphasis is on the loss of we-feelings and on the oppression of a particular kind of intense I-feelings, while the other side of the coin, namely increasing possibilities of expressing I-feelings of another kind - more managed ones, but still relaxed and informal - is neglected. When we-groups have lost their cohesion and grip on individuals, directly exerted group pressures and group constraints have diminished. This has opened new possibilities for individual initiative and for asserting oneself as an individual - that is, to claim the right to be evaluated on the basis of individual achievement and personality. 'Pessimists of the mind' tend to underestimate the fact that in this century, chances for I-feelings to find expression have increased, while related dangers - like being expelled from the old wegroup and having to suffer their they-feelings and punitive sanctions - have diminished.

Nevertheless, these chances may not be experienced as such. They may be experienced as demands, and with some justification: as extreme expressions of social and psychological distance were banned and gradually vanished, and as contrasts in behaviour and feeling diminished, respect and self-respect indeed demanded a more individual articulation and profiling, including a demand for what is generally experienced as an inner authenticity and an authentic profundity. Increased sensitivity in these matters makes for a presentation of self that is soon experienced as artificial and superficial, as just the mask of an 'inner-directed Macho' or an 'inner-directed Amazon'. At the same time, people have found themselves more often in situations where they feel obliged to create and to endure differences, even contradictions 
between their emotions and their emotion management. As hierarchical differences have diminished, people have increasingly forced each other toward striking a more subtle and harmonious balance between all kinds of opposing motives and behaviour, like directness and tactfulness, simplicity and sophistication, compelling and being compelled, attracting and repelling, being charming and being daunting. Simultaneously, the art of producing and maintaining a gratifying and harmonious balance, one that to a certain extent surpasses or sublimates ${ }^{10}$ these tensions, has become more demanding. ${ }^{11}$ In addition to a widening range of alternatives for behaviour and the expression of emotions, the process of informalization at the same time entails an increasing demand to manage emotions in more flexible and differentiated ways, to be able to negotiate in all kinds of situations, with all sorts of people, and to proceed through mutual consent.

In this century, the social and individual pressures that people exert upon themselves and each other have increased rather rapidly and strongly and, simultaneously, ambivalences and insecurities have intensified, together with the wish to be liberated from them. Therefore, these changes have often been interpreted as predominantly oppressive, and ambivalence has often found expression in an irritated romantic way. Both feelings of irritation and idealization, romanticization or nostalgia occur as a pair - no nostalgia without irritation and vice versa - and, depending upon the balance between the two, the reaction may be called irritated nostalgia or nostalgic irritation. As a pair, they show the relationship between constraints and dreams of liberation or ideals. Any excursus on the history of utopias and romantic ideals may illustrate this relationship. ${ }^{12}$ Passions and anxieties, utopias and 'dystopias', ideals and spectres mirror each other. Whether projected into the past or into the future, they always betray the social and individual tensions of the figuration in which they were created.

The tradition of cultural criticism in the social sciences provides many examples. For instance in Christopher Lasch's The Culture of Narcissism irritation with the present 'culture of narcissism' is combined with a nostalgia for some past in which fathers were thought to be still righteous and demanding (Lasch 1979). In Philippe Ariès's work on attitudes toward dying, irritation with the present 'taboo' on death is combined with a nostalgia for some past in which death was thought to be 'both familiar and near, evoking no great fear or awe' (Ariès 1974: 13). In this century, the social and psychological distance between social groups in Western societies have greatly diminished, as have the contrasts in their behaviour and feeling. Irritation may well dominate the relationship between particular established groups and groups of outsiders, such as Old Rich and nouveau riche, cosmopolitans and provincials, but in their irritation as well as in 
their nostalgic longing for 'better days', they show that the power differences and the hierarchical distance between them - as vanguards and rearguards in relation to the dominant code - have diminished. Their irritated nostalgia or nostalgic irritation expresses, in other words, the degree of integration of these groups within their society. The irritation or moral indignation of people in a rearguard often betrays their lack of confidence and fear of losing self-control if they admitted, even to themselves, being tempted by what they see as 'dangerous behaviour': they are afraid to set the fox - in themselves - to watch the geese, afraid opportunity makes them a thief. The presence of such a temptation indicates that the rearguard they represent is not very far removed from the dominant standard. By analogy, the feelings of superiority and the inclination to boast of those in a vanguard often demonstrate that they too are not very different from the people in a rearguard. Displays of superiority often show how small and incipient the lead in emotion management is. Through earlier experiments and experiences, people representing a vanguard may have succeeded in overcoming their 'tyro-fears' and in bringing the chances and dangers of a particular form of behaviour under stronger control, while 'regressionfears' may still be prominent. For example, as a boy I was often impatiently irritated by the 'clumsy' progress of my brother, eighteen months younger than myself, in a new phase or a new field in his life, exactly because I was painfully reminded of my own clumsiness in a very recent past. Quite often I would have simply preferred to deny that I had been just like him. The same regularity in the development of emotion management can be discerned in the relationship between groups of people. The irritated moral indignation of Europeans about the burning of Salmon Rushdie's book and the threat to kill the author may serve as an example. Many of these Europeans have in their own lifetime experienced the burning of books and large-scale killing, but they prefer not to be reminded of all that by an outsider and a representative of a rearguard like Khomeini, and they react with revulsion if they - as Europeans - are identified with all this killing and burning. But precisely for that reason the feeling of irritation is so strong. By thus touching upon this sensitive we-identity of Europeans, Khomeini has succeeded, although most probably unintentionally, in changing the Second World War to some extent into a European War. In this case, the irritation can be seen as an expression of the tensions that accompany rising degrees of interdependence and integration of these societies within the world. As such, it was an incident in and an indication of the process of global integration that is occurring.

As long as processes of differention and integration continue to develop in the same direction and social and psychological bonds expand and intensify, the social and psychological tensions of these bonds will also increase and with them the intensity of the longing to defy these 
tensions in spontaneous, authentic, relaxed and informal conduct. On the other hand, unrealistic expressions of this ideal are likely to be brought more strongly under the same individual and social constraints as the passions that may provoke physical and sexual violence. No matter how strongly the longing for a more simple life with little self-restraint intensifies, the function of self-regulation as a weapon in the status struggle will be simultaneously reinforced, and identity and self-respect will have become more dependent upon it. Becoming simple and innocent again is impossible anyway; the road back is blocked. Only ambivalences and balances, like 'sophisticated simplicity' or 'noble authenticity' (controlled decontrolling) are open as realistic ideals - a price to be paid for peace and welfare.

Although feelings of ambivalence, insecurity and disorientation will to some extent accompany each new round in the process of self-distantiation, articulating and emphasizing one's distinctive features still seems to have become a sport and an art, and increasing numbers of people seem to have become more and more aware both that they have to put their minds and hearts into it, and of how it is to be done.

In every new spurt of the civilizing process there is a moment in which most people have come to take the new ways of curbing and self-regulating for granted, and more or less automatically live up to this expectation. At that time, the social compulsion to wear this 'mask' of emotion management has been transformed into 'second nature'. For most of the rest it may be done 'secretly'. Norbert Elias once used the metaphor 'second nature' to indicate what had already happened to court aristocrats at the beginning of the eighteenth century, and he continued: 'The increasing compulsion to self-constraint opens new pleasures to them, new enrichments and refinements, in short new values, together with new oppressions and dangers. At any rate, self-control becomes for them a high personal value' (Elias 1983: 241). As the longing for a simpler and more passionate kind of life intensified, simultaneously the function of self-control as a weapon in the status struggle has been reinforced, which means that the meaning and justification of one's life, one's respect, self-respect and identity have become more dependent upon this controlling capacity.

\section{Informalization and the sociology of emotions}

In a long-term process of formalization, standards of behaviour and feeling have expanded and differentiated. This long-term trend probably reached its peak in the 'Victorian Era', together with the 'stiff upper lip', to be followed in the twentieth century by a dominant process of informalization. ${ }^{13}$ An 'emancipation of emotions' was already clearly present in Impressionism 
and this trend became dominant in the fin de siècle and the Edwardian period. The 'Roaring Twenties' and the 1960s and 1970s showed strong spurts in the same direction: the relaxation and differentiation of codes of behaviour and feeling continued. More closely examined, the relaxation and differentiation of these codes have continued in short-term phases of informalization and formalization. The way this has happened can be expressed photographically: the stiff studio poses of the 1940s and 1950s of serious looking people, dressed in their Sunday best, were replaced in the 1960s and 1970s by spontaneous snapshots of relaxed and smiling people, dressed according to (spare) time and place (Oosterbaan 1988). At the end of the 1970s, when opportunities for collective ascent on the social ladder declined and each individual became more dependent upon his or her own qualities in the status competition, people gave way more easily again to the incentive to show they were well off, and also how well off. In the 1980s, (in addition to a continued appreciation of relaxed and informal behaviour) the fear of excessive familiarity and insufficient social distance strengthened, and the presentation of self became somewhat more serious and reserved, and many changed (back) from sweater and jeans into suit and tie - a return to old traditions, while integrating new ones: a formalization of earlier informalized behaviour (Wouters 1987).

The 'soft look' bra, introduced in the 1970s, when many women had altogether given up wearing bras, may be taken as another, playful illustration of the same process. This bra supports the breasts, as did the old type of 'hard look' bra that was still common in the 1950s and early 1960s, without removing the image of 'free' flesh and the visual suggestion of nipples. This triplet - hard look bra, no bra, soft look bra - can be taken as another example of the formalization of earlier informalized behaviour.

In a long-term process of formalization, expression, display and, at its zenith, even references to emotions, especially those that could provoke physical and sexual violence, were curbed and tabooed. In processes of democratization, the rise in mutually expected self-restraints has been accompanied by increasing curiosity about sex, violence and death, which in the course of centuries have been put behind the social and individual scene; the emotions involved are increasingly allowed - both individually and socially speaking - to re-enter consciousness. In the long-term process of informalization, a collective search for these hidden emotions and motives has been going on, and in this process emotions have gained acceptance as important guides for behaviour and knowledge, whereas before they were predominantly seen as a source of transgression and misbehaviour. Before the last spurt of informalization in the 1960s and 1970s, provocations and challenges to sexual and violent emotions, indeed emotions in general, were 
predominantly viewed as dangerous. Expressions like 'to become emotional' still have the connotation of a lack of control over emotions, of being swept away by them. Expressions like these are reminiscent of this very danger and of the rigid social control that served to counter it. In this century, the emancipation of the lower classes has run in tandem with an 'emancipation of emotions' or, to put it slightly differently, further integration of lower classes within the social structure has run in tandem with further integration of 'lower' or 'animalic' impulses and emotions within personality structures.

Whereas in the long-term process of formalization, the view of emotions as dangerous dominated, today, emotions are even seen as having a very important signal function - this was an insight of Freud - and their potential dangerousness is viewed and formulated much more strongly in terms of a balance: mastery over the art of emotion management in such a way that 'domestic policy' and 'foreign policy' stay in harmony (Elias 1982: 294). Or in other words, that both the risk of losing the signal function of feeling and the risk of losing the signal function of display are avoided (Hochschild 1983: 21). ${ }^{14}$ This also means that the perspective on emotions and impulses as both dangerous and vital has increased; dangerous because they may get out of control and bring the miseries of imprisonment and commital in an asylum, and vital for their 'survival signal function' and as a source of pleasure. In a similar way, the presentation of self will also be more and more experienced as both a burden and a pleasure. ${ }^{15}$ The need for such a perspective may explain the rising popularity of and demands for 'reflexivity' as 'cultural capital'. In this development, a growing number of people have become increasingly aware of the necessity of managing emotions and of developing a 'dramaturgical perspective' (Goffman 1959), a perspective that focuses on differences and contradictions between emotions and utterances or displays of emotions in the presentation of self. According to Hochschild, this means that 'the point of interest has moved inward. What fascinates us now is how we fool ourselves' (Hochschild 1983: 192). Just as Freud's 'discovery' of 'animalic' emotions and motives occurred at the peak of their repression and denial, by analogy, the 'sociology of emotions' began to spread when rejection of repression and denial of emotions seemed to reach its height.

The rise of interest in the study of emotions, whether as a 'sociology of emotions', a 'history of emotions' or in any other form, can be seen as a recent expression of the trend from the end of last century onward towards acknowledging the vital importance of emotions and emotion management. While in processes of social democratization and integration the experience of physical safety and material security has been spreading, the studies of political 
and economic changes, dealing respectively with changes in the management of violence and of scarce means (money), has come to be perceived more and more as incomplete without the study of changes in emotion management. There is increasing awareness of a gap that has been rising between social processes and social theories, as well as of the origin of this gap: a poor integration of emotions and emotion management into theoretical frameworks. Most probably, it is the rising importance of emotion management in the intensified struggle for respect and selfrespect that has led social scientists to perceive an 'anomaly' (Kuhn) in their theories.

Around the 1950s, these changes had begun to attract considerable attention in the academic world, as its foremost example, David Riesman's classic book The Lonely Crowd shows. At that time, however, the key concept was still morals, not yet emotions or emotion management. Riesman, for instance, focused on the growth of 'moral relativism' and directed his attention to a specific change: internalized controls of a fixed kind - "inner-direction" changed from being an advantage into being a handicap. According to Riesman's well known statement, social changes now required a system of internalized controls that incorporated moral relativism; they necessitated "other-direction", a self regulation that was acutely sensitive and responsive to group norms while recognizing the limited relevance of all moral imperatives.

Another academic who focused on changing morals in the 1940s and 1950s was Martha Wolfenstein. In the early 1950s, she coined the concept of 'fun morality,' the emergence of which, she writes, 'may be observed in the ideas about child training of the last forty years', and she concludes:

The attitude toward play is related to the conception of impulses and the belief about the good and the pleasant. Where impulses are dangerous and the good and pleasant are opposed, play is suspect. ... Where formerly there was felt to be the danger that, in seeking fun, one might be carried away into the depths of wickedness, today there is a recognizable fear that one may not be able to let go sufficiently, that one may not have enough fun (Wolfenstein 1955: 168/171/174).

Wolfenstein's discussion of 'fun morality' preceded the much broader discussion on the 'Expressive Revolution' and 'permissive society' of the 1960s and 1970s. These discussions as well as studies of 'mentalities' and 'everyday life' clearly show that attention in the academic world was moving in the direction of what was later called the study of emotions. But on the whole, in and particularly outside the academic world, a rather personal and involved version of this field of study was still dominant: the 'sensitivity' and 'encounter' movement. It took several years before the social changes of the 'Expressive Revolution' had a serious impact on the 
academic world and were somehow theoretically incorporated in comparatively detached studies. Only from the mid 1970s onwards (and Kemper is certainly right to 'speculate that sociologists were responding to the Zeitgeist of the decade of the 1960s' (Kemper 1990: 4)) has the subject been called emotions and emotion management. From then on, an increasing number of social scientists have become aware that, as Scheff puts it, most of their theories 'are biased toward rational or material models of causation' (Scheff 1990: 294). This development may be viewed as a sign of the concentration stage (Mannheim 1928, cf. Kilminster 1991: 112) or an 'integration spurt' particularly within the social sciences of sociology, psychology and history, but - I think it is important to note - also between these social scientists and novelists. In the 1970s, a Dutch sociologist interested in the American 'small town' compared sociological studies with novels on that subject. He remarked that 'in general, sociologists pay little attention to the emotions of the people they study, whereas emotions are quite central for the novelist' (Hollander, undated: 38); that may still be true, but the recent attention paid to the social aspects of emotions and emotion management suggests that this difference is at least diminishing.

On the other hand, the integration spurt is in itself quite diverse. At the moment there exists such a large diversity of contributions and there are so many different approaches and research agendas presented (cf. Kemper 1990) that the attempt at 'bringing emotions back in' seems to stumble over its very success. Therefore, I would like to emphasize that any attempt at synthesis will have to do justice to the fact that, as bonds of cooperation and competition between individuals and their groups change, not only do the dominant social theories and definitions of the problems and chances of living together change, but so also do the codes of behaviour and feeling, and the emotional make-up of the individuals concerned. It is exactly this interconnectedness that makes the study of collective changes in emotion management important and promising. In order to live up to the promise of this study, nostalgic tendencies will have to be further controlled. Up to now, too many studies in this field have been directed towards a search for 'real' and 'authentic' emotions (cf. Wouters 1989). ${ }^{16}$ Such a nostalgic search neglects the fact that every single individual is born in a rather undifferentiated and pliable emotional condition. Within the relationships in which they grow up, from the very beginning of their lives, all develop emotional impulses and counter-impulses that are more or less attuned to the dominant standards of behaviour and feeling of their society. This is the way in which they learn to articulate and manage emotions and impulses; and it is for this reason that emotions are recognized for their vital 'survival signal function'. In order to clearly bring forward the indissoluble tie between emotions and emotion management, much could be said in favour of 
changing the symbolic expression of this kind of study from the 'sociology of emotions' to the 'sociology of emotional management'.

I thank Stephen Mennell for correcting my English.

\section{$\underline{\text { REFERENCES }}$}

Ariès, Philippe (1974) Western Attitudes toward Death, Johns Hopkins University Press, Baltimore.

Bailey, Joe (1988) Pessimism, Routledge, London/New York.

Bataille, George (1971) Les larmes d'Eros, Paris.

Bennis, Warren G. and Philip E. Slater (1968) The Temporary Society, Harper \& Row, New York.

Dunning, Eric, Patrick Murphy, Tim Newburn and Ivan Waddington (1987) Violent Disorders in twentieth-century Britain, in: George Gaskelland and Robert Benewick (ed.), The Crowd in Contemporary Britain, Sage, London.

Elias, Norbert and John L. Scotson (1965) The Established and the Outsiders, Frank Cass \& Co., London.

Elias, Norbert (1978 and 1982) The Civilizing Process, Volume I and II, New York.

Elias, Norbert (1983) The Court Society, Oxford.

Elias, Norbert and Eric Dunning (1986) Quest for Exitement, Oxford.

Elias, Norbert (1989) Studien über die Deutschen. Machtkämpfe und Habitusentwicklung im 19. und 20. Jahrhundert, Edited by Michael Schröter, Frankfurt a. M.

Elias, Norbert (1991) Mozart. Zur Soziologie eines Genies, Edited by Michael Schröter, Suhrkamp, Frankfurt a. M.

Goffman, Erving (1959) The presentation of self in everyday life, Double Day Anchor Books, New York.

Harré, Rom (ed.) (1986) The Social Construction of Emotions, Basil Blackwell, Oxford and New York.

Hobsbawm, Eric and Terence Ranger (eds.) (1983) The Invention of Tradition, Cambridge.

Hochschild, Arlie R. (1983) The Managed Heart, University of California Press, Berkeley.

Hollander, A.N.J. den (undated), Het Amerikaanse Landstadje in de romanliteratuur en in de sociologie, De Bataafse Leeuw.

Hunnik, Marian van (1989) Jongeren over cocaïnegebruik, Jeugd en Samenleving 19/8(August): 500-513.

Kapteyn, Paul (1980) Taboe, macht en moraal in Nederland, Arbeiderspers, Amsterdam.

Kasson, John F. (1990) Rudeness \& Civility. Manners in Nineteenth-Century Urban America, Hill and Wang, New York.

Kemper, Theodore D. (ed.) (1990) Research Agendas in the Sociology of Emotions, New York, State University of New York Press.

Kilminster, Richard (1991) Structuration theory as a world view, in Chr. G.A. Bryant and D. Jary (eds.), Giddens' Theory of Structuration: A Critical Appreciation, Routledge, London: 74-119.

Mannheim, Karl (1952, German 1928) 'Competition as a Cultural Phenomenon', Essays in the Sociology of Knowledge, Routledge and Kegan Paul, London. 
Lasch, Christopher (1979) The Culture of Narcissism, New York.

Mennell, Stephen (1985) All Manners of Food. Eating and Taste in England and France from the Middle Ages to the Present, Basil Blackwell, Oxford.

Oosterbaan, Warna (1988) article on photography in NRC-Handelsblad 30-12-'88.

Rapport der regeerings-commissie inzake het dansvraagstuk (1931) The Hague.

Riesman, David with N. Glazer and R. Denney (1950), The Lonely Crowd, Yale University Press, New Haven.

Ritter jr., P.H. (1933) De Drang der zinnen in onzen Tijd (The Urge of Senses in our Time), Scheltema \& Giltay, Amsterdam.

Scheff, Thomas J. (1990) Socialization of Emotions: Pride and Shame as Causal Agents, in Kemper 1990: 281-304.

Stearns, Carol Zisowitz and Peter N. Stearns (1986) Anger. The Struggle for Emotional Control in America's History, The University of Chicago Press, Chicago and London.

Stearns, Peter N. (1989) Suppressing Unpleasant Emotions: The Development of a TwentiethCentury American Style, in: Andrew E. Barnes and Peter N. Stearns (ed.) Social History and Issues in Human Consciousness, New York University Press, New York and London: 230-261.

Stearns, Peter N. and Timothy Haggerty (1991) The Role of Fear: Transitions in American Emotional Standards for Children, 1850-1950, The American Historical Review 1991: 6394.

Stolk, Bram van and Cas Wouters (1987) Frauen im Zwiespalt. Beziehungsprobleme im Wohlfahrtsstaat, Suhrkamp, Frankfurt am Main.

Swaan, A. de (1985) Kwaliteit is klasse, Bakker, Amsterdam.

Wolfe, Tom (1963) The Kandy-Kolored Tangerine-Flake Streamline Baby, Farrar, Straus \& Girouz, New York.

Wolfe, Tom (1968a) The Electric Kool-Aid Acid Test, Farrar, Straus \& Girouz, New York.

Wolfe, Tom (1968b) The Pump House Gang, Farrar, Straus \& Girouz, New York.

Wolfe, Tom (1976) Move Gloves \& Madmen, Clutter \& Vine, Farrar, Straus \& Girouz, New York.

Wolfenstein, Martha (1955, orig. 1951) Fun Morality: An Analysis of Recent American Child Training Literature, in Margaret Mead and Martha Wolfenstein (eds.), Childhood in Contemporary Cultures, University of Chicago Press, Chicago.

Wouters, Cas (1986) Formalization and Informalization: Changing Tension Balances in Civilizing Processes, Theory, Culture \& Society 3(2): 1-18.

Wouters, Cas (1987) Developments in the Behavioural Codes between the Sexes: The Formalization of Informalization in The Netherlands, 1930-85, Theory, Culture \& Society 4(2-3): 405-27.

Wouters, Cas (1989) The Sociology of Emotions and Flight Attendants: Hochschild's Managed Heart, Theory, Culture \& Society 6(1): 95-123.

Zutphen van Dedem, Mevr. van (1928) Goede Manieren (Good Manners), Logon, Amersfoort.

\section{NOTES}

1. An example of this trend towards increasing style competition is the multitude of rapidly changing terms and expressions that the young use today for classifying each other according to their own style and taste in clothing, music and behaviour - terms and expressions like 'disco', 'house', 'hip-hop' and 'punk'. To some extent, this kind of classification disguises the style and taste of their parents - that is, their class origin. In 
the days of 'cap in hand', the characteristics of social class were much more obvious and uniform.

2. In the course of civilizing processes fears of physical attack are increasingly replaced by social fears of shame and embarrassment in increasingly interdependent, complex and internally pacified societies. Shame and embarrassment are clear examples of inferiority feelings, but any change in the 'threshold' of shame and embarrassment has implications for both inferiority and superiority feelings: Shame is 'a form of displeasure or fear which arises characteristically on those occasions when a person who fears lapsing into inferiority can avert this danger neither by direct physical means nor by any other form of attack. This defencelessness against the superiority of others... results from the fact that the people whose superiority one fears are in accord with one's super-ego, with the agency of self-constraint implanted in the individual by others on whom he was dependent, who possessed power and superiority over him... It is a conflict within his personality; he himself recognizes himself as inferior. He fears the loss of the love or respect of others, to which he attaches or has attached value' (Elias 1982: 292/3, my italics).

3. Until the 1930s, Dutch etiquette books still contained separate paragraphs on 'good behaviour' toward social superiors and inferiors. These paragraphs disappeared, and even references to these differences became increasingly indirect. A similar trend has been observed in the USA: "Almost all books on manners in colonial America... contain an emphasis on "superiors" and "inferiors" that would dramatically lessen in the course of the nineteenth and twentieth century...' (Kasson 1990: 12).

4. The way Goffman used the term impression management indicates that he especially refers to the secret part of emotion management.

5. Taste and style may be widely debated - in processes of informalization the connected fears seem to have been brought under firm enough control for these debates even to be enjoyed - but such debates turn sour when related status aspects are touched upon. This is 'not done'; these aspects are generally denied, repressed and rejected as a tasteless and cynical reduction of the level of debate: 'What the world needs now is a manual for artistic codes in theatre, concert halls and museums. First lesson: conceal such a need completely, for the right stuff and the right tone come naturally, don't they?' (A. de Swaan 1985: 32-3)

6. This does not mean that the motive to keep and maintain the social and psychological distances and differences between status superiors and inferiors has disappeared, nor that it has lost any of its importance. Its explanatory power can be illustrated from the way in which some New Yorkers avoid using the subway. From this remnant of their far greater opportunities in former times of avoiding 'contaminating contact with the spiritually inferior and the repugnant', Tom Wolfe generalizes: 'in fact much of the status symbolism of New York grows out of the ways the rich and the striving manage to insulate themselves, physically, from the lower depths. They live up high to escape the dirt and the noise. They live on the corners to get the air.' (Wolfe 1963: 297)

7. Cf.: 'the structure of fears and anxieties is nothing other than the psychological counterpart of the constraints which people exert on one another through the intertwining of their activities' (Elias 1982: 327).

8. The expression 'nostalgie de la boue, or romanticizing of primitive souls' is explained as 'a nineteenthcentury French term that means, literally, "nostalgia for the mud." (Wolfe 1970: 32) The "downward perspective' (Wouters 1986) that characterizes this form of nostalgia, was also often expressed in the 'quest for risks' manner. An example, again derived from Wolfe, is presented in the group around Ken Kesey, author of One Flew Over the Cuckoo's Nest (1962), who invited and 'entertained' the Hell's Angels: '... it once and for all put Kesey and the Pranksters above the category of just another weirdo intellectual group. They had broken through the worst hangup that intellectuals know - the real-life hangup. Intellectuals were always hung up with the feeling that they weren't coming to grips with real life. Real life belonged to all those funkey spades and prize fighters and bullfighters and dock workers and grape pickers and wetbacks. Nostalgie de la boue. Well, the Hell's Angels were real life. It didn't get any realer than that, and Kesey had pulled it off' (Wolfe 1968a: 158).

9. In 1955, Martha Wolfenstein (1955: 175) observed: 'Today we have attained a high degree of tolerance of impulses, which at the same time no longer seem capable of producing such intense excitement as formerly'. 
10. For an outline of a sociological theory on sublimation, see Elias 1991: 78-87.

11. The balance is certainly lost if one thinks in terms of dichotomies, and proceeds by declaring one side of the balance as 'false' or 'a fraud': 'this hedonism is a fraud; the pursuit of pleasure disguises a struggle for power... Hedonism... originates not in the pursuit of pleasure but in a war of all against all, in which even the most intimate encounters become a form of mutual exploitation.' (Lasch 1979: 125/7)

12. A familiar example is the process in which knights lost their domains and became courtiers. In this process, the imaginative form of literature called romances was born. Courtiers found an outlet for the social and psychological tensions of living at court in the dreamworld of Arcadia; in pastoral romance and play, an unrestrained simplicity and relaxed directness of countrylife was romanticized (cf. Elias 1983).

13. Trends toward formalization and informalization are likely to have been operative throughout history; there will have always been groups trying to enforce formal rules, and others trying to resist them or evade them. If one such group has a winning streak for any length of time, a corresponding phase of formalization or informalization will be dominant. In the long run too, one of these trends may be stronger than the other, corresponding to long-term phases of formalization or informalization.

14. In 1950 Riesman still largely opposed 'inner-directedness' and 'other-directedness'; today, Riesman's twin concepts seem less appropriate to describe successive periods and their characteristic type of personality, since they appear to be closely related as the two synchronic, co-existing poles of an increasingly intensified tension balance.

15. 'More play in work also means more work in play, until all acts become both playful and instrumental, public and private...' (Bennis and Slater 1968: 88). These writers continue: 'and no sphere of human expression is altogether uncontaminated by duty,' but this only emphasizes one side and should be completed by adding 'nor unrelated to play and pleasure.'

16. At the other extreme, many studies in this field have been directed towards a search for emotion words and emotion vocabularies, and their cultural relativism can be characterized as a kind of literary reductionism. For an example, see Harré 1986. 